\title{
Correction to: New Advances in Human X Chromosome Status from a Developmental and Stem Cell Biology
}

\author{
Benjamin Patterson ${ }^{1} \cdot$ Yoshiaki Tanaka $^{1} \cdot$ In-Hyun Park $^{1}$ (D)
}

Published online: 19 January 2018

(C) The Korean Tissue Engineering and Regenerative Medicine Society and Springer Science+Business Media B.V., part of Springer Nature 2018

Correction to: Tissue Eng Regen Med (2017) 14(6):643-652 https://doi.org/10.1007/s13770-017-0096-4

Unfortunately, Acknowledgements section was missing in the originally published article.

It is now provided here as follows:
Acknowledgements We thank all the Park laboratory members for their helpful comments and active discussion. I.-H.P. was supported in part by the NIH (GM0099130-01, GM111667-01), the CSCRF (13SCB-YALE-06, 14-SCC-YALE-01, 16-RBM-Yale-04), and the KRIBB/KRCF (NAP-09-3).

The original article can be found online at https://doi.org/10.1007/s13770-017-0096-4.

In-Hyun Park

inhyun.park@yale.edu

1 Department of Genetics, Yale Stem Cell Center, Yale School of Medicine, New Haven, CT 06520, USA 